Chronologia (2021) vol. 3 no. 1 hal. 44-52

http://dx.doi.org/10.22236/jhe.v3i1.7158

E-ISSN: 2686-0171

\title{
Potret Pembelajaran Sejarah diampu Pendidik di luar Latarbelakang Akademik Sejarah
}

\section{Portrait of History Learning Taught by Educators Outside Academic Background of History}

\author{
Rafia Zulfah $^{1}$, Daradinanti Octavia Mauri ${ }^{2}$, Qorry Nadhirotun Zahro ${ }^{3}$ \\ $1 \bowtie 23$ Universitas Muhammadiyah Prof. DR. HAMKA
}

E-mail: zulfah904@gmail.com ${ }^{\circledR}$, daradinanti9@gmail.com, qorrynadhirotun@gmail.com

Diterima: 23 Juni 2021 | Direvisi: 31 Juli 2021 | Diterbitkan: 31 Juli 2021

ARTICLE INFO

Keywords:

Educator,

History,

Student.

\section{Kata Kunci:}

Pendidik,

Sejarah,

Siswa.
ABSTRACT

Education is the greatest power to create a future that is better than today. Historical education is one of the branches of social science that is important to learn to improve and maintain the spirit of nationalism for the nation's generations. Historical awareness is triggered by the process of learning history, however, the fact that there are history educators who do not come from appropriate educational backgrounds can be one of the main factors in the problem of increasing interest in the history of the Indonesian nation today. On these problems the author will discuss with qualitative research methods with a phenomenological approach as a support for writing. This article aims to discuss the ideal strategy and concept of history learning in order to revitalize the quality of educators and students in the branch of historical science. As well as to increase awareness of the history of the Indonesian people about the importance of studying history to know our identity as part of the Indonesian nation. By paying more attention to educators, they can change the paradigm of unattractive history learning into learning that has moral values about this nation, it is hoped that history learning will again become one of the priorities of educators and students in the learning process to study history. The results obtained in this study are in the form of problems in learning history in schools or various things that become obstacles to learning history in a school as well as ideal history learning.

Pendidikan adalah suatu kekuatan terbesar untuk menciptakan suatu masa depan yang lebih baik dari hari ini. Pendidikan sejarah adalah salah satu cabang ilmu pengetahuan sosial yang penting untuk dipelajari untuk meningkatkan dan menjaga semangat nasionalisme para generasi bangsa. Kesadaran sejarah dipicu dari proses pembelajaran sejarah, namun demikian kenyataan bahwa adanya tenaga pendidik sejarah yang tidak berasal dari latar pendidikan yang sesuai dapat menjadikan salah satu faktor utama dalam permasalahan peningkatan minat sejarah bangsa Indonesia pada masa kini. Atas permasalahan tersebut penulis akan membahas dengan metode penelitian kualitatif dengan pendekatan fenomenologi sebagai penunjang penulisan. Artikel ini bertujuan untuk membahas strategi dan konsep pembelajaran sejarah yang ideal guna merevitalisasikan kualitas pendidik dan peserta didik dalam cabang ilmu kesejarahan. Serta untuk meningkatkan kesadaran sejarah masyarakat Indonesia tentang arti penting mempelajari sejarah untuk mengenal identitas kita sebagai bagian dari bangsa Indonesia. Dengan memperhatikan lebih pada tenaga pendidik dapat mengubah paradigma tentang pembelajaran sejarah yang tidak menarik menjadi sebuah 
pembelajaran yang memiliki nilai - nilai moral tentang bangsa ini, diharapkan pembelajaran sejarah akan kembali menjadi salah satu prioritas pendidik dan peserta didik dalam proses pembelajaran untuk mempelajari sejarah. Hasil yang didapatkan dalam penelitian ini berupa problematika pembelajaran sejarah di sekolah atau berbagai hal yang menjadi penghambat pembelajaran sejarah di suatu sekolah serta pembelajaran sejarah yang ideal.

\section{PENDAHULUAN}

Menurut Kuntowijoyo (2013) dalam bukunya yang terkenal "Pengantar IImu Sejarah" mengungkapkan bahwa salah satu fungsi sejarah yakni sebagai ilmu. Sejarah sebagai ilmu dapat berkembang dengan berbagai cara, seperti : (1) Perkembangan dalam filsafat (2) Perkembangan dalam teori sejarah

Perkembangan dalam ilmu-ilmu bantu sejarah (4) Perkembangan dalam metode sejarah. Sejarah juga adalah cara untuk mengetahui masa lampau. Ruang lingkup sejarah tidak hanya berada pada masa lampau, sejarah dapat mencakup masa lalu, masa sekarang dan masa depan. Dengan belajar sejarah kita dapat mengetahui perjuangan pahlawan bangsa ini demi menciptakan kehidupan yang lebih layak tanpa penjajahan seperti yang terjadi dimasa lampau. Kehidupan itu yang kita rasakan sekarang. Sejarah juga sebagai cara untuk mempersiapkan masa depan. Dengan mempelajari masa lampau yang telah berlalu kita dapat memprediksikan dan mempersiapkan masa depan yang lebih baik, agar kesalahankesalahan pada masa lampau tidak lagi terulang.

Sejarah memiliki arti penting bagi pendidikan di sekolah. Karena jika diajarkan secara baik dan benar sejarah berguna untuk membentuk sikap dan mental generasi muda agar memiliki sifat nasionalisme serta mampu memotivasi para siswa baik melalui intisari rangakaian peristiwa di dalamnya ataupun melalui dengan tokoh-tokoh dalam kisah sejarah tersebut (Hardjasaputra, 2015). Namun, pada kenyataannya kesadaran sejarah semakin terkikis seiring perkembangan zaman. Dizaman modern seperti sekarang ini peminat sejarah semakin menipis. Masyarakat kini menganggap sejarah adalah sesuatu yang bersifat klasik dan tidak selaras dengan zaman modern. Padahal, kita yang hidup dimasa ini kelak akan menjadi masa lalu dimasa yang akan datang.

Faktor pandangan miring akan pendidikan sejarah tersebut semakin terlihat jelas dengan peminat sejarah yang semakin menipis baik dalam ilmu sejarah maupun pendidikan sejarah padahal jurusan sejarah ataupun pendidikan sejarah memiliki prospek yang cukup luas (Jenoche, 2021). Akan tetapi jika kembali ke topik permasalahan, hal inilah yang kemudian membuat pihak sekolah mengizinkan guru-guru yang bukan berasal dari jurusan pendidikan sejarah mengajarkan materi sejarah di kelas. Alhasil, faktor inilah yang kemudian melahirkan pembelajaran sejarah yang kurang maksimal dan cenderung membosankan. Hingga berujung pada pandangan negatif siswa akan mata pelajaran sejarah di kelas.

Atas dasar persoalan tersebutlah, maka pada artikel kali ini, peneliti akan membahas salah satu problematika dalam proses belajar mengajar pelajaran sejarah disekolah yaitu pembelajaran sejarah yang diajarkan oleh 
Zulfah, Mauri, Zahro, 2021, Potret Pembelajaran Sejarah. . .

tenaga pendidik yang bukan berasal dari jurusan pendidikan sejarah. Mengutip pernyataan Steel didalam (Widja, 2018) pembelajaran sejarah adalah "the teaching on history is in fact a skilled and complex process which demands a highly professional approach". Dalam pernyataan tersebut tergambar jelas bahwa pembelajaran sejarah membutuhkan kemampuan personal yang tinggi yang belum tentu bisa dilakukan oleh semua orang. Salah satu caranya adalah dengan menyampaikan pelajaran sejarah oleh pendidik yang berlatarbelakang akademik sejarah.

Kemudian tidak dapat dipungkiri juga apabila jika yang mengajarkan materi sejarah benarbenar berasal dari lulusan pendidikan sejarah, akan dapat mendongkrak berbagai macam persoalan yang terjadi selama pembelajaran sejarah berlangsung. Karena teknik penyampaian, kedalaman materi, penguasaan kelas, ataupun retorika dari seorang guru sejarah yang dididik selama bertahun-tahun pasti jauh lebih terlatih ketimbang guru sejarah baru yang berasal dari jurusan ilmu lainnya. Maka dari itu penelitian ini penting untuk dilaksanakan karena berhubungan dengan pandangan seorang terhadap ilmu sejarah dan juga pemahaman siswa akan ilmu sejarah.

\section{METODE}

Metode yang digunakan adalah metode penelitian kualitatif dengan pendekatan fenomenologi. Pemilihan metode ini dikarenakan menurut (Hasbiansyah, 2008) fenomenologi adalah suatu analisis deskriptif serta instropeksi mendalam individu dalam bentuk keasadaran akan suatu pengalaman yang dirasakan secara langsung. Fenomenologi adalah suatu kajian filosofis yang melukiskan segala bidang pengalaman hidup manusia. Manusia selama hidupnya mengalami berbagai macam pengalaman oleh karna itu, kajian fenomenalogi tidak pernah berakhir. Selain itu fenomenologi juga diartikan sebagai suatu studi yang berupaya untuk menganalisis secara mendalam tentang segala bentuk pengalaman manusia. Sehingga dalam hal ini fenomenologi menjadi pendekatan yang tepat untuk digunakan dalam membahas permasalahan di artikel ini (Helaluddin, 2017).

Adapun proses yang dilakukan oleh penulis dalam menghasilkan karya ini adalah dengan tahapan pengumpulan sumber baik sumber lisan dan tulisan. Dimana sumber tulisan yang kami gunakan adalah buku-buku, jurnal dan artikel ilmiah yang berkaitan dengan tema penelitian yang kita lakukan. Kemudian, datadata tersebut kami pilah lagi untuk mendapatkan data yang valid. Data yang valid tersebut kemudian dilakukan penafsiran untuk menghasilkan sebuah pemahaman dan menemukan titik inti pembahasan yang selaras antar sumber. Ditambah dengan pengalaman penulis sebagai peserta didik dahulu yang mengalami pembelajaran sejarah ini tidak dibimbing oleh guru-guru yang berasal dari akademik sejarah memperkuat pembahasan dalam artikel ini. Selanjutnya adalah tahapan penulisan artikel ilmiah yang berasal dari data data yang sudah seruji serta paradigma penulis tentang tema penelitian ini menghasilkan sebuah artikel penelitian ini.

\section{HASIL DAN PEMBAHASAN \\ PROBLEMATIKA \\ PEMBELAJARAN \\ SEJARAH DI SEKOLAH}


Problematika pembelajaran adalah suatu kendala, persoalan atau masalah dalam proses pembelajaran yang harus dipecahkan agar proses pembelajaran berjalan dengan maksimal. Dalam dunia akademik problematika pembelajaran begitu banyak dan faktor penyebabnya juga beragam (Rosihuddin, 2015). Maka dari itu dalam tulisan ini yang akan dibahas hanya sebatas pembelajaran sejarah di sekolah saja, tidak dengan problematikproblematika lainnya yang ada di mata pelajaran lain ataupun jenjang lain yang lebih tinggi.

Dalam artikelnya Joko Sayono (2013) menjabarkan beberapa problematika pembelajaran sejarah disekolah, diantaranya yaitu :

1. Pembahasan dari materi sejarah cukup luas dengan waktu pelajaran yang relatif sedikit.

2. Pembelajaran sejarah di SD dan SMP yang diakumulasikan dengan pembelajaran sosial lain seperti ekonomi, sosiologi dan geografi dalam rumpun sosial.

3. Tidak semua guru mata pelajaran sejarah berasal dari latarbelakang akademik sejarah.

4. Belum adanya pemanfaatan media pembelajaran yang baik.

Berdasarkan permasalahan yang dibagi oleh Sayono tersebut, jika diamati secara mendalam akan menyiratkan peran guru sejarah memiliki kemampuan yang besar dalam mengatasi setiap permasalahan tersebut. Mulai dari menyusun secara matang strategi yang tepat untuk mengatasi keterbatasan waktu dalam menjelaskan materi, sampai dengan memaksimalkan pemanfaatan media pembelajaran. Tidak menutup kemungkinan juga dalam mengatasi masalah pada poin dua peran guru sangat dibutuhkan. Namun yang menjadi permasalahan disini bagaimana bila guru tersebut tidak mengenyam pendidikan sejarah sebelumnya. Maka dari itu pada sub bab ini poin pembahasan lebih diutamaan poin nomor tiga terkait Tidak semua guru mata pelajaran sejarah berasal dari latarbelakang akademik sejarah.

Seperti yang tertuang dalam bab pendahuluan bahwa pembelajaran sejarah adalah "the teaching on history is in fact a skilled and complex process which demands a highly professional approach." (Widja, 2018). Dalam pernyataan tersebut tergambar jelas bahwa pembelajaran sejarah membutuhkan kemampuan personal yang tinggi yang belum tentu bisa dilakukan oleh semua orang. Salah satu caranya adalah dengan menyampaikan pelajaran sejarah oleh pendidik yang berlatarbelakang akademik sejarah.

Alasan penting mengapa penyampaian materi harus dilakukan oleh ahlinya karena pembelajaran yang disampaikan oleh tenaga pendidik di luar bidangnya akan terasa kurang ideal jika dibandingkan dengan pendidik yang berasal dari bidang akademik yang sesuai. Hal ini tidak terlepas dari pengalaman dari sang pendidik itu sendiri, seorang yang ahli dan telah lama bergelut pada bidangnya akan memiliki persiapan yang matang dalam melaksanakan pembelajaran dan telah mengetahui metodemetode apa saja yang tepat untuk digunakan dalam kelas dengan mayoritas siswa memiliki pola tertentu. Selain itu pemahamannya terhadap materi yang diajarkan juga akan jauh berbeda dan makna utama dalam sejarah dapat tersampaikan dengan baik apabila sang 
Zulfah, Mauri, Zahro, 2021, Potret Pembelajaran Sejarah. . .

pengampu berasal dari jurusan sejarah berbanding terbalik apabila bukan berasal dari sejarah, makna yang disampaikan kemungkinan terkaburkan.

Permasalahan ini juga akan semakin rumit dan besar apabila tenaga pendidik tersebut tidak melaksanakan pekerjaannya secara profesional, seperti tidak adanya usaha untuk lanjut ke program studi pendidikan sejarah, tidak mengikuti berbagai macam kegiatan pelatihan ataupun seminar yang berhubungan dengan sejarah atau kurangnya daya literasi. Ketidakprofesionalan inilah yang lantas membuat pembelajaran sejarah di kelas akan semakin rumit dan berujung pada jenuhnya peserta didik dalam mengikuti pelajaran sejarah (Slamento, 2014).

Adapun beberapa kekurangan dan permasalahan lainnya yang dapat timbul apabila pengampu mata pelajaran sejarah tidak berasal dari latarbelakang akademik ilmu sejarah, diantaranya yaitu:

1. Materi pembelajaran yang disampaikan kurang mendalam

2. Guru sebagai tenaga pendidik tidak memberikan emosionalnya dalam memberikan pembelajaran sejarah karena kekurangannya menguasai materi

3. Tidak tersampaikanya nilai-nilai moral dari pembelajaran sejarah kepada peserta didik.

4. Pembelajaran sejarah tidak bisa membangkitkan semangat nasionalisme peserta didik

5. Semakin runtuhnya kesadaran sejarah masyarakat Indonesia dimasa depan

Dengan demikian jika mengacu pada berbagai permasalahan tersebut, sudah jelas bahwa indikator dalam pembelajaran sejarah akan sulit terwujud. Beberapa indikator tersebut, diantaranya seperti:

1. Tujuan, sasaran dan substansi pada segisegi pembelajaran sejarah yang bersifat normatif

2. Nilai dan makna pembelajaran sejarah yang lebih tertuju pada kepentingan pendidikan ketimbang ilmiah murni

3. Pembelajaran sejarah harus memuat unsur pokok yang bertanggungjawab pada masa depan bangsa

4. Pembelajaran sejarah tidak hanya menyajikan pengetahuan fakta pengalaman kolektif dari masa lampau melainkan juga memberikan latihan berpikir kritis dalam memetik makna dan nilai dari peristiwa yang dipelajari (Amelia, 2015).

Maka dari itu demi memenuhi indikator tersebut sudah sepantasnya apabila tugas untuk mengampu pembelajaran sejarah diserahkan kepada tenaga ahlinnya. Hal ini dimaksudkan agar setiap indikator tersebut dapat terpenuhi secara maksimal dan proses pembelajaran berlangsung secara kreatif dan efektif. Walaupun terkesan tidak terlalu fatal, namun jika dikaji secara mendalam permasalahan ini adalah suatu masalah yang serius.

Ketika guru sejarah gagal mengajarkan sejarah secara ideal dan setiap indikator yang ditargetkan gagal terpenuhi, akan membuat setiap siswa yang kelak akan terjun ke masyarakat memiliki nilai kesadaran sejarah yang rendah. Ditambah dengan gempuran masuknya budaya asing melalui dunia maya, hal ini lantas akan membuat generasi muda menjadi jauh lebih mudah terpengaruh oleh doktrindoktrin, paham ataupun ideologi dari budaya luar yang beberapa diantaranya dapat 
mengancam kestabilan bangsa Indonesia. Maka dari itu peran pembelajaran sejarah menjadi vital disini demi memupuk rasa nasionalisme agar para generasi muda tidak hanyut terbawa arus globalisasi (Warto, 2017).

Dengan demikian sudah sepantasnya apabila tugas mengampu pembelajaran di kelas diberikan kepada ahlinya, bukan orang lain yang tidak mengenyam secara akademik mata pelajaran tersebut. Namun tidak dapat disangkal bahwa untuk menerapkan kebijakan ini perlu adanya koordinasi yang kuat dalam pengurusan sekolah. Kemudian untuk sekolah negeri perlu adanya koordinasi yang intens juga dengan dinas pendidikan provinsi agar tidak kekurangan tenaga pendidik yang sesuai bidang keahliannya. Sedangkan untuk sekolah swasta peran yayasan cukup berpengaruh disini dalam menentukan kebijakan terkait tenaga ahli yang sesuai bidangnya, maka dari itu pihak sekolah swasta juga harus melakukan komunikasi yang intens dengan yayasan ataupun dinas pendidikan agar di sekolah tersebut setiap mata pelajaran yang ada diampu oleh tenaga ahli yang sesuai bidangnya.

\section{PEMBELAJARAN SEJARAH YANG IDEAL}

Pembelajaran sejarah di Sekolah terlihat kurang diminati baik dari segi peserta didik yang menerima pembelajaran dan pendidik yang memberikan pembelajaran sejarah disekolah. Pada pendidikan tingkat SD dan SMP pembelajaran sejarah masuk dalam rumpun mata pelajaran IPS yang tergabung dengan mata pelajaran ekonomi, geografi dan sosiologi (Rahmad, 2016). Karena IPS adalah gabungan beberapa mata pelajaran maka pendidik mata pelajaran IPS bisa berasal dari rumpun ilmu sosial selain sejarah. Padahal, penguasaan materi sesuai dengan bidangnya sangat diperlukan untuk menciptakan pembelajaran yang ideal. Tenaga pendidik yang berasal dari pendidikan ekonomi contohnya, belum tentu menguasai pembelajaran sejarah dengan mendalam untuk nantinya disampaikan kepada peserta didik, begitupula sebaliknya. Contoh tersebut merupakan permasalahan yang tercipta akibat proses pembelajaran yang diampu oleh bukan tenaga ahlinya.

Sebelum mengkaji secara mendalam terkait pembelajaran sejarah yang ideal, maka perlu dipahami terlebih dahulu tujuan dar pembelajaran sejarah. Pembelajaran sejarah di sekolah para intinya bertujuan untuk mencapai kesadaran sejarah. Widja (2018) menjelasakan bahwa konsep dari kesadaran ialah sebuah kesadaran untuk mampu dan mau belajar dari sejarah (pengalaman atas peristiwa dimasa lampau) sebagai motivasi dalam merespon setiap tantangan kehidupan menuju kehidupan yang lebih baik dimasa kini dan dimasa depan. Semangat pembelajaran sejarah seperti dijelaskan oleh Winarno Surakhmad (2009) ialah proses pendidikan yang "Memanusiakan, Membudayakan dan Menglndonesiakan". Pernyataan ini kemudian diperjelas oleh Sayono (2013) yang menjabarkan bahwa pembelajaran sejarah akan melahirkan kesadaran tentang hakikat perkembangan budaya dan peradaban manusia di muka bumi.

Berdasarkan pada tujuan pembelajaran sejarah tersebutlah, indikator-indikator akan pembelajaran sejarah mulai dibentuk, seperti: untuk mengembangkan kemampuan berpikir 
Zulfah, Mauri, Zahro, 2021, Potret Pembelajaran Sejarah. . .

kritis, mengembangkan rasa ingi tahu, mengembangkan kreatifitas, mengembangkan sikap kepahlawanan dan kepemimpinan, membangun dan mengembangkan semangat kebangsaan, sampai dengan mengembangkan kepedulian sosial (Hasan, 2012).

Beberapa indikator tersebutlah yang kemudian akan dikembangkan dan menjadi landasan untuk mengukur keberhasilan pembelajaran sejarah di kelas. Apabila indikatorindikator tersebut berhasil terpenuhi, maka dapat dikatakan pembelajaran sejarah di kelas terlaksana secara ideal. Akan tetapi dalam pelaksanaannya tidak semudah ini karena terdapat berbagai macam problematika yang menjadi tantangan menuju pembelajaran sejarah yang ideal.

Salah satu problematika yang masih terjadi, terus terulang dan belum dapat diselesaikan yakni terkait tenaga pendidik yang sesuai bidangnya. Walaupun dirasa sederhana, namun hal ini melahirkan berbagai rentetan panjang problematika pembelajaran sejarah di sekolah (Aminah, 2015). Karena dalam pembelajaran sejarah peran guru begitu penting untuk mengatasi berbagai macam permasalahan yang dapat timbul tanpa diduga atau memang telah ada sejak lama, seperti materi yang kontroversial, teorinya yang sedikit atau materi yang terlalu banyak. Semua masalah tersebut dapat teratasi apabila guru yang mengajar pembelajaran sejarah adalah guru yang sesuai kompetensinya. Sekalipun ada permasalahan baru yang timbul, misalnya terkait media yang digunakan, hal ini dengan mudah dapat teratasi yakni cukup dengan mengikutkan guru tersebut dalam sebuah pelatihan.
Dengan demikian, maka dapat dipahami bahwa peran dari seorang guru pengampu yang sesuai bidangnya begitu penting demi mewujudkan pembelajaran sejarah yang ideal. Dikarenakan seorang guru tidak hanya dituntut untuk mengajar saja melainkan juga mendidik dan semua itu harus berjalan dengan maksimal agar mampu memenuhi setiap indikator yang telah ditetapkan. Memang tidak menutup kemungkinan apabila terdapat guru yang mampu mengajar dengan baik walau tidak dari jurusan yang sesuai, akan tetapi secara nyata penyampaian makna yang diberikan serta tingkat kedalaman materi yang dimiliki oleh tersebut perlu dipertanyakan. Apalagi setelah kurikulum 2013 dirilis dan mata pelajaran sejarah mengalami perluasan materi pelajaran. Hal ini akan semakin mempersulit para pendidik yang bukan berasal dari jurusan pendidikan sejarah untuk mengajarkan materi yang telah ada apalagi jika harus disesuaikan dengan berbagai indikator pembelajaran sejarah secara ideal. Oleh sebab itu, sudah sepantasnya apabila setiap sekolah semakin memperketat kebijakannya dalam aturan tenaga ahli yang mengajar.

\section{KESIMPULAN}

Pembelajaran sejarah sering dianggap membosankan, karena terkenal akan metode pembelajarannya yang hanya mengandalkan ceramah atau bahkan selalu menghafal. Keadaan demikian dapat tercipta karena berbagai faktor, salah satu faktor tersebut yakni karena guru pengampunya bukan berasal dari jurusan sejarah. Mungkin hal ini terdengar sederhana, karena sejarah banyak individu yang berpendapat sejarah cukup dipelajari dengan 
membaca saja tanpa ada kesulitan lainnya, layaknya ilmu eksak.

Faktor pandangan miring inilah yang lantas, membuat mata pelajaran sejarah sering diampu oleh guru diluar kompetensinya tanpa memikirkan dampak yang tercipta begitu vatal. Karena pembelajaran yang disampaikan oleh tenaga pendidik di luar bidangnya akan terasa kurang maksimal jika dibandingkan dengan pendidik yang berasal dari bidang akademik yang sesuai. Hal ini tidak terlepas dari pengalaman dari sang pendidik itu sendiri, seorang yang ahli dan telah lama bergelut pada bidangnya akan memiliki persiapan yang matang dalam melaksanakan pembelajaran dan telah mengetahui metode-metode apa saja yang tepat untuk digunakan dalam kelas dengan mayoritas siswa memiliki pola tertentu. Selain itu pemahamannya terhadap materi yang diajarkan juga akan jauh berbeda dan makna utama dalam sejarah dapat tersampaikan dengan baik.

Maka dari itu peran dari seorang guru pengampu yang sesuai bidangnya begitu penting demi mewujudkan pembelajaran sejarah yang efektif dan dapat memenuhi target. Sehingga sudah sepantasnya apabila sekolah mendukung kebijakan ini. Selain demi meningkatkan mutu sekolah, kebijakan terhadap mata pelajaran yang harus diampu oleh ahlinya juga menjamin masa depan generasi muda akan lebih baik.

\section{DAFTAR PUSTAKA}

Amelia, C. A. (2015). Peranan Pembelajaran Sejarah Dalam Penanaman Sikap Nasionalisme Siswa Kelas Xi Ips Sma Negeri 1 Pecangaan. Indonesian Journal of History Education, 3(2), 47-54.
Hardjasaputra, A. S. (2015). Sejarah Dan Pembangunan Bangsa. Jurnal Artefak, Vol 3(1), 1-4.

Hasan, S. H. (2012). Pendidikan Sejarah Untuk Memperkuat Pendidikan Karakter. Paramita: Historical Studies Journal, 22(1). https://doi.org/10.15294/paramita.v22i1.1875

Hasbiansyah, O. (2008). Pendekatan Fenomenologi: Pengantar Praktik Penelitian dalam IImu Sosial dan Komunikasi. Mediator: Jurnal Komunikasi, 9(1), 163-180. https://doi.org/10.29313/mediator.v9i1.1146

Helaluddin. (2017). Mengenal Lebih dekat dengan Pendekatan Fenomenologi: Sebuah Penelitian Kualitatif. Retrieved from https://www.google.com/search?q=fenomenol ogi+mengkaji+tentang \&rlz=1C1CHBD_idID92 5ID925\&oq=fenomenologi+mengkaji+tentang \&aqs=chrome..69i57j0i333|3.5245j0j4\&sourc eid=chrome $\&$ ie $=$ UTF -8

Jenoche. (2021). Sepi Peminat, Prospek Kerja Jurusan IImu Sejarah Terbuka Lebar.

Kuntowijoyo. (2013). Pengantar IImu Sejarah (Cetakan 1). Yogyakarta: Tiara Wacana.

Nur Aminah, A. (2015). Banyak Guru tak Sesuai Kompetensinya. Retrieved July 29, 2021, from Republika.co.id website: https://republika.co.id/amp/nlpfgp16

Rahmad. (2016). Kedudukan IImu Pengetahuan Sosial ( IPS ) pada Sekolah Dasar. Muallimuna: Jurnal Madrasah Ibtidaiyah, 2(1), 67-78. Retrieved from https://media.neliti.com/media/publications/22 2455-kedudukan-ilmu-pengetahuan-sosialips-pa.pdf

Rosihuddin, M. (2015). Pengertian Problematika Pembelajaran. Retrieved July 28, 2021, from Banjir Embun website: https://www.banjirembun.com/2012/11/penge rtian-problematika pembelajar an html

Sayono, J. (2013). Pemelajaran Sejarah di Sekolah: Dari Pragmatis ke Idealis. Sejarah Dan Budaya, 07(01), 9-17.

Slamento. (2014). Permasalahan-Permasalahan terkait dengan Profesi Guru SD. Scholaria, $4(3), 1-12$.

Surakhmad, W. (2009). Pendidikan Nasional: Strategi dan Tragedi. Jakarta: Penerbit Buku Kompas.

Warto. (2017). Menumbuhkan Kesadaran 
Zulfah, Mauri, Zahro, 2021, Potret Pembelajaran Sejarah. . .

Sejarah Genarasi Muda. Diskusi Sejarah UNY. Yogyakarta: Universitas Negeri Yogyakarta. Retrieved from http://pendidikansejarah.fis.uny.ac.id/sites/pendidikansejarah.fis.uny.ac.id/files/KESADARAN SEJARAH GENERASI MUDA.pdf

Widja, I. G. (2018). Pembelajaran Sejarah Yang Mencerdaskan Suatu Alternatif Menghadapi Tantangan dan Tuntutan Jaman yang Berubah. Jurnal Pendidikan Sejarah Indonesia, 1(2), 117-134. https://doi.org/10.17977/um033v1i22018p117 